\title{
O processo de cicatrização influenciado pelo hipotireoidismo e pelo envelhecimento. Estudo da cicatrização de anastomoses intestinais, em ratos
}

\author{
Maria de Lourdes Pessole Biondo-Simões ${ }^{2}$, Sergio Ossamu Ioshii ${ }^{3}$,Ana Denise Zazula ${ }^{4}$, Rachel Biondo-Simões ${ }^{5}$
}

Biondo-Simões MLP, Ioshii SO, Zazula AD, Biondo-Simões R. O processo de cicatrização influenciado pelo hipotireoidismo e pelo envelhecimento. Estudo da cicatrização de anastomoses intestinais, em ratos. Acta Cir Bras [serial on line] Available from: URL: htt:/ /www.scielo.br/acb.

RESUMO - Objetivo: O envelhecimento da população tem feito crescer o número de intervenções em pacientes idosos, sendo o hipotireoidismo, ainda que sub-clínico, é uma situação bastante comum nestes doentes. O presente estudo busca conhecer a influência do hipotireoidismo no processo de cicatrização de anastomoses colônicas em ratos idosos. Método: Utilizaram-se 96 ratos Wistar, machos; 48 deles jovens e 48 velhos. Metade dos animais jovens e metade dos velhos eram eutireoideanos e metade eram hipotireoideanos. Conseguiu-se o hipotireoidismo por meio de tireoidectomia total. Após 30 dias, fez-se uma laparotomia mediana seguida de colotomia transversa de cólon esquerdo com anastomose término-terminal e laparorrafia. No 3. ${ }^{\circ}$ 7. ${ }^{\circ}$ e $14 .{ }^{\circ}$ dias de pósoperatório, sorteados, 6 animais de cada grupo, que foram submetidos à eutanásia. Fez-se a análise macroscópica das anastomoses, da resistência e estudo histopatológico. Resultados: Não se detectaram deiscências e o ganho de resistência e a evolução histológica geral, considerando epitelização e reação inflamatória foi semelhante em todos os grupos. A análise do conteúdo total de colágeno revelou, no $3 .^{\circ}$ dia, que as anastomoses de jovens e velhos tinham o mesmo comportamento, porém via-se menos colágeno nas anastomoses dos animais com hipotireoidismo ( $\boldsymbol{J N} \boldsymbol{x} \boldsymbol{J H} \boldsymbol{p}=\mathbf{0 , 0 0 0 0 ;} \boldsymbol{V N} \boldsymbol{x} \boldsymbol{V H} \boldsymbol{p}=\mathbf{0 , 0 0 0 0})$. Este comportamento se manteve no 7. ${ }^{\circ} \mathrm{e}$ no $14 .^{\circ}$ dia. A presença de colágeno I era menor nas anastomoses dos animais hipotireoideanos no 3 . $^{\circ}$ dia $(\boldsymbol{J N} \boldsymbol{x} \boldsymbol{J H} \boldsymbol{p}=\mathbf{0 , 0 0 1 5} ; \boldsymbol{V N}$

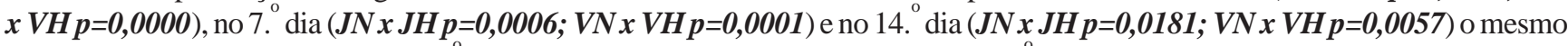
acontecendo com o colágeno III, no 3. dia $(x J H p=0,0007 ; \boldsymbol{V N} x \boldsymbol{V H} p=0,0260)$, no 7. $\operatorname{dia}(J N x J H p=0,0160 ; V N x V H p=0,2670)$ e no 14. ${ }^{\circ}$ dia $(\boldsymbol{J N} \boldsymbol{x} \boldsymbol{J H} \boldsymbol{p}=\mathbf{0 , 0 0 0 0 ;} \boldsymbol{V N} \boldsymbol{x} \boldsymbol{V H} \boldsymbol{p}=\mathbf{0 , 0 0 3 0})$. Conclusão: A análise dos resultados permite concluir que existe diminuição da concentração de colágeno decorrente da baixa da síntese e retardo de maturação das cicatrizes das anastomoses muito mais às custas do hipotireoidismo do que do envelhecimento.

DESCRITORES: Cicatrização de feridas. Cólon. Colágeno. Hipotireoidismo. Envelhecimento.

\section{Introdução}

A melhor compreensão do binômio saúde-doença, assim como os avanços tecnológicos, permitindo diagnósticos mais precisos e terapêuticas mais eficientes, as campanhas de prevenção de doenças e o acesso ao atendimento de saúde, tem melhorado as condições de saúde e aumentado a longevidade do homem. Como conseqüência têm aumentado o número de pessoas idosas nos hospitais e de procedimentos cirúrgicos. Muitos cirurgiões acreditam que a idade avançada produza mudanças fisiológicas intrínsecas que resultam em dano à cicatrização.

Riou et $\mathrm{al}^{2}$ e Carlson ${ }^{3}$, analisando estudos multicêntricos, concluíram que a idade era um fator de risco para o processo de cicatrização. Vários autores descreveram deficiências da cicatrização e mesmo deiscências em pacientes idosos.

Pesquisadores relataram, em idosos, atraso da reepitelização ${ }^{4,5}$ e demonstraram diminuição do colágeno tanto em seres humanos como em animais ${ }^{6,7}$. Kletsas et al ${ }^{8}$ não encontraram evidências da relação de dependência da idade com o declínio da resposta de fibroblastos humanos aos vários fatores de crescimento. Para eles a capacidade de sintetizar esta mantida e as alterações estariam na dependência de fatores sistêmicos, como os níveis de hormônios.

Não se pode esquecer que indivíduos idosos, muitas vezes, apresentam-se com doenças cardiovasculares, diabetes ou neoplasias. Não é incomum encontrarem-se com desnutrição, deficiências vitamínicas, alterações neuroendócrinas e utilizando medicamentos, os mais variados, e que estas situações podem ser responsáveis por distúrbios da reparação tecidual.

O envelhecimento leva a alterações tireodianas sendo relativamente freqüente, o estado de hipotireoidismo. Oliveira relatou que $24,1 \%$ dos pacientes idosos por ela estudados em seu trabalho de tese apresentavam hipotireoidimo e Schindler ${ }^{10}$ observou que o envelhecimento aumenta a pos-

1. Estudo desenvolvido na Pontifícia Universidade Católica do Paraná

2. Professora Titular de Técnica Operatória - Metodologia Científica da PUCPR e Coordenadora da Disciplina de Técnica Cirúrgica e Cirurgia Experimental da Universidade Federal do Paraná. Titular do CBC e membro da SBCP.

3. Professor de Patologia Experimental da UFPR e da PUCPR.

4. Aluna de Iniciação Científica do Curso de Medicina da PUCPR.

5. Aluna do Curso de Medicina da Universidade do Extremo Sul Catarinense (UNESC). 
sibilidade de hipofunção tireoideana, especialmente nas mulheres. Segundo este autor após a menopausa 2,4\% das mulheres apresentam clínica de disfunção e 23,2\% têm doença subclínica.

Alexander et al ${ }^{11}$ relataram que pacientes submetidos à laringectomia, após terem recebido radioterapia, apresentavam deficiências cicatriciais com o aparecimento de fístulas. Embora se acredite que a tireóide tenha boa resistência à irradiação, muitos de seus pacientes com complicações estavam hipotireoideanos e melhoraram após a administração de hormônio tireoideano.

É descrito na literatura que o hipotireoidismo interfere na síntese, no metabolismo e na solubilidade do colágeno ${ }^{12-14}$. Sabe-se, que em modelo animal, o hormônio tireoideano participa da modulação da expressão do gen para o colágeno I ${ }^{15}$ e foram identificados mecanismos moleculares envolvidos na indução do hormônio tireodeano regulando o RNA mensageiro para o colágeno $\mathrm{I}^{16}$.

Estudos, feitos em ratos com hipotireoidismo induzido com 5-propul,2-thiuracil e cirúrgico, demonstraram diminuição da resistência das cicatrizes abdominais e da concentração de colágeno além de atraso da organização ${ }^{17,18}$.

O hormônio tireoideano estaria associado com a proliferação e a secreção dos fibroblastos. A supressão da secreção dos hormônios tireoideanos causaria distúrbio da ativação metabólica nos tecidos e na síntese do colágeno, se estendendo da fase inflamatória até a fase proliferativa ${ }^{18}$. Deficiências de cicatrização da parede abdominal aumentam a possibilidade de infecção e morte. Quando se verificam deiscências de anastomoses digestivas a situação é ainda mais grave.

Em estudo de nossa linha de pesquisa observou-se que, embora existam diferenças no processo de cicatrização de jovens e velhos, a idade, por si só, não é a causa da falência da cicatrização, tanto nas feridas da parede abdominal, quanto nas das anastomoses colônicas ${ }^{19}$. É provável que distúrbios relacionados com o envelhecimento sejam responsáveis pelos danos causados à reparação. Como o hipotireoidismo é uma situação bastante comum nos indivíduos idosos passamos a desenvolver o presente estudo, que procura reconhecer a influência da falta dos hormônios produzidos pela tireóide sobre a cicatrização de anastomoses de cólon, em ratos jovens e velhos .

\section{Métodos}

Para o desenvolvimento deste estudo foram respeitadas as orientações do Colégio Brasileiro de Experimentação Animal (COBEA) e as determinações da Lei Federal 6.638.

Utilizaram-se 96 ratos machos, Rattus norvegicus albinus, Rodentia mammalia, da linhagem Wistar, PUCPR, 48 eram animais adultos jovens com média de idade de 110 dias e 48 eram animais velhos, com média de idade de 760 dias. Os ratos jovens pesaram $239,93 \pm 18,78$ gramas ( $\%$ do desvio padrão $=7,80$ ) e os velhos 361,06 \pm 39,34 gramas ( $\%$ do desvio padrão $=10,89)$. O grupo jovem pesou em média 239,93 \pm $18,78$ gramas (\% do desvio padrão $=7,80)$ e o dos velhos $361,06 \pm 39,34$ gramas (\% do desvio padrão $=10,89$ ).

Sob anestesia conseguida com $0,1 \mathrm{ml} / 100 \mathrm{~g}$ de peso de uma solução de $1,0 \mathrm{ml}$ de quetamina $(50 \mathrm{mg} / \mathrm{ml})$ com $1,0 \mathrm{ml}$ de xilazina $(20 \mathrm{mg} / \mathrm{ml})$, administrada intra-muscular, se fez uma tireoidectomia total induzindo estes animais ao estado de hipotireoidismo. Nos ratos jovens e velhos normais, sob a mesma anestesia, fez-se uma cervicotomia para simular o mesmo grau de stress. Após a recuperação anestésica estes animais, marcados, foram mantidos em gaiolas apropriadas para a espécie, no ambiente do biotério, com temperatura de $20^{\circ} \pm 2^{\circ} \mathrm{C}$, ciclo claro/escuro de 12 horas e umidade do ar a própria do ambiente. Todas as caixas estavam colocadas à igual distância da fonte de luz. Receberam ração padrão comercial e água suplementada de cálcio.

Após 30 dias, foram novamente anestesiados e pesados. Se fez uma incisão mediana de $4 \mathrm{~cm}$ e uma colotomia transversa esquerda, a $2 \mathrm{~cm}$ da reflexão peritoneal. Seguiu-se a reconstrução do trânsito com anastomose término-terminal, com um único plano de síntese, extramucoso, com 8 pontos feitos com fio monofilamentar de náilon 6.0, fechados com 4 seminós. Fez-se, em seguida a laparorrafia com dois planos de síntese, o primeiro peritônio-músculo-aponevrótico e o segundo o da pele, com sutura contínua de fio monofilamentar de náilon 4.0.

No 3..$^{\circ}$, 7 $^{\circ}$ e $14 .^{\circ}$ dia de pós-operatório, escolhidos por sorteio, 6 animais de cada grupo foram submetidos à eutanásia com dose letal do anestésico.

Realizou-se uma nova laparotomia e se examinou a cavidade em busca de deiscências e aderências. Em seguida ressecouse $4 \mathrm{~cm}$ do colón que continha a anastomose.

Conheceu-se a resistência das cicatrizes intestinais utilizando-se teste manométrico. Limpava-se o segmento de cólon ressecado com solução salina $0,9 \%$ e colocava-se dentro de um recipiente com solução salina. Este recipiente apresentava, na região média de uma de suas paredes internas, uma entrada de ar, com válvula unidirecional, de forma triangular. Fixava-se a extremidade proximal do segmento de cólon em torno da entrada de ar, de modo que a estrutura triangular ficasse dentro da luz do cólon, por uma ligadura dupla com cadarço cirúrgico. Desta forma o cateter de oxigênio introduzido na entrada de ar adentrava à luz do cólon. Na extremidade distal realizava-se sutura em bolsa; as extremidades do fio eram ancoradas no fundo do recipiente, de modo que o segmento do cólon ficasse em posição horizontal e totalmente submerso no líquido. Introduzia-se, então, um cateter de 0,7 mm de diâmetro e $70 \mathrm{~mm}$ de comprimento pela entrada de ar, o qual penetrava a luz do cólon por $20 \mathrm{~mm}$. Este cateter apresentava extremidade proximal de 2 vias. Conectava-se a primeira via a um cilindro de oxigênio, o qual fornecia fluxo de $1 \mathrm{l} / \mathrm{min}$. Ligava-se a segunda via a um transdutor e este a um monitor cardíaco digital multicanal (biomonitor 7, marca 
BESE $^{\circledR}$ ), capaz de registrar os valores de pressão intraluminais. Considerava-se a pressão de ruptura, a pressão intraluminal máxima no momento em que se verificava vazamento do oxigênio, detectado prlo borbulhar do oxigênio no líquido.

As peças, fixadas em formalina à $10 \%$, foram enviadas para o Laboratório de Patologia Experimental para a confecção de lâminas. Os cortes histológicos foram corados pela Hematoxilina-eosina para identificação dos aspectos gerais e pela técnica do Sirius-red para a identificação dos colágenos I e III.

Examinaram-se os cortes histológicos corados pelo Siriusred em microscópio, utilizando-se fonte de luz polarizada. Analisaram-se as imagens captadas por uma câmara Sony ${ }^{\circledR}$ CCD 101, enviadas a um monitor Sony Trinitron ${ }^{\circledR}$ colorido, congeladas e digitalizadas por uma placa digitalizadora Oculus ${ }^{\circledR}$ TCX (coreco), pelo aplicativo Image Plus 4.5 para Windows em computador Pentium III. As fibras colágenas mais espessas e fortemente birrefringentes apresentam-se coradas de tons de laranja a vermelho e representam o colágeno I, enquanto as fibras mais finas e dispersas, fracamente birrefringentes se apresentam coradas de verde e representam o colágeno III ${ }^{(20)}$. Para cada lâmina leram-se 3 campos com ampliação de $200 \mathrm{X}$, sobre a área da cicatriz e obteve-se a média da leitura.

Submeteram-se os resultados à estudo estatístico. Para as tabelas 2 x 2 empregou-se o teste paramétrico Qui-quadrado.
Quando restrições a ele estavam presentes, empregou-se o teste, não paramétrico, Exato de Fisher. Para a comparação de médias utilizou-se o teste paramétrico $t$ de student. Quando os números analisados não constituíam curva gaussiana, este teste foi substituído pelo teste não paramétrico de Mann Whitney. Fixou-se p =0,05 ou 5,0\% como nível para rejeição da hipótese de nulidade.

\section{Resultados}

No exame da cavidade abdominal não se observou a presença de líquido livre ou septado na cavidade peritoneal que pudesse configurar a presença de peritonite ou abscesso, em nenhum dos animais. Aderências estiveram presentes em todas as anastomoses, com diferentes intensidades.

A análise macroscópica não evidenciou deiscência em nenhuma das anastomoses e em nenhum dos grupos. Assim, tanto animais jovens como velhos eutireoideos e hipotireoideos suportaram as anastomoses.

Os segmentos de cólon ressecados que continham a anastomose, submetidos à teste manométrico, mostraram ganho gradual de resistência à pressão. No $3 .^{\circ}$ dia a resistência era mínima e semelhante em todos os grupos. No 7..$^{\circ}$ dia pode-se ver que as anastomoses ganharam resistência o que continuou até o $14 .^{\circ}$ dia, sem diferenças significantes entre os grupos (Figura 1).

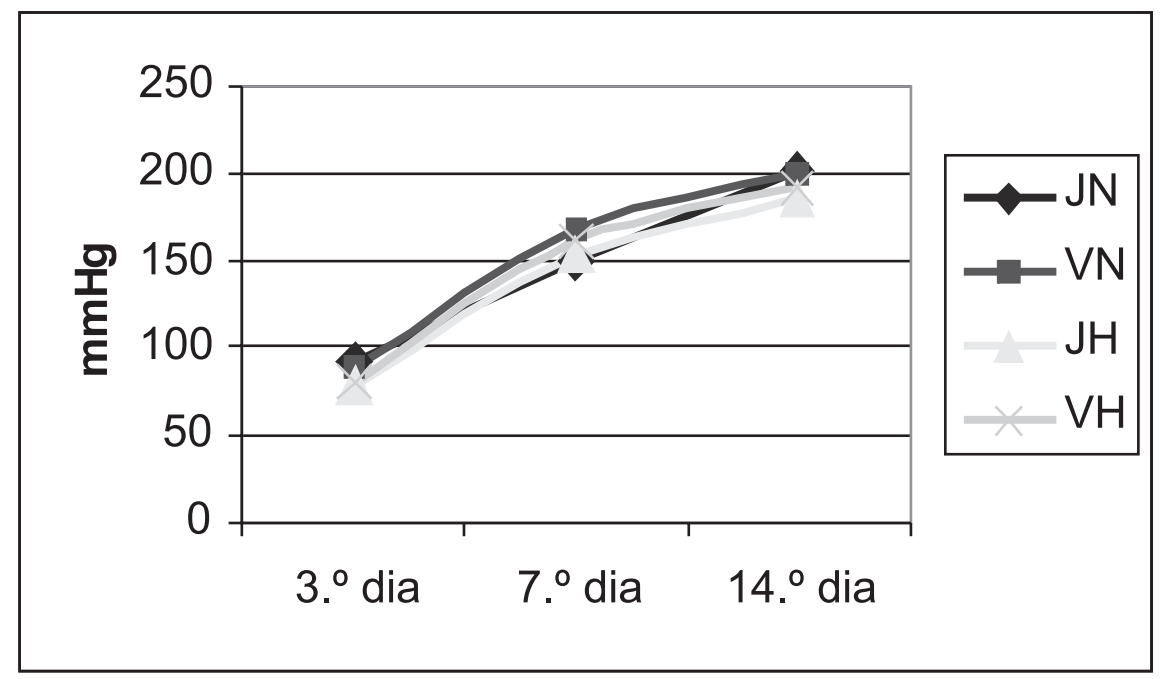

FIGURA 1 - Médias das resistências nos 4 grupos e nos 3 tempos

( $\mathrm{JN}=$ jovens normais, $\mathrm{VN}=$ velhos normais, $\mathrm{JH}=$ jovens com hipotireoidismo, $\mathrm{VH}=$ velhos com hipotireoidismo) Teste $t$ de student

3. ${ }^{\text {dia }}$ - JN x VN p =0, 4954, JN x JH p =0,2120, VN x VH p =0,4940, JH x VH p =0,8715

7. ${ }^{\circ}$ dia $-\mathrm{JN} \times \mathrm{VN} \mathrm{p}=0,0597, \mathrm{JN} \times \mathrm{JH} \mathrm{p}=0,1518, \mathrm{VN} \times \mathrm{VH} \mathrm{p}=0,4642, \mathrm{JH} \times \mathrm{VH} \mathrm{p}=0,3107$

$14 .^{o}$ dia $-\mathrm{JN} \times \mathrm{VN} p=0,8910, \mathrm{JN} \times \mathrm{JH} p=0,2440, \mathrm{VN} \times \mathrm{VH} p=0,5733, \mathrm{JH} \times \mathrm{VH} p=0,6000$

A evolução microscópica geral das anastomoses, avaliada pela coloração da hematoxilina-eosina, se fez de modo semelhante nos cólons dos animais jovens e velhos, eutireoideos ou hipotireoideos.
No 3. ${ }^{\circ}$ dia, os cortes histológicos demonstravam solução de continuidade de todas as túnicas da parede intestinal, exceto do peritônio, onde se via, com freqüência, tecido adiposo acolado. O esporão interno apresentava áreas de necrose coagulativa e podia-se ver, na superfície, fibrina e células 
inflamatórias. Aárea compreendida entre as margens da lesão estava ocupada por células inflamatórias e reepitelização marginal estava presente.

No 7. ${ }^{\circ}$ dia observou-se tendência, nas anastomoses dos animais com hipotireoidismo, ao atraso da reepitelização, porém o tamanho da amostra não permitiu esta afirmativa. No $14 .^{\circ}$ dia todas as anastomoses dos animais jovens estavam reepitelizadas e apenas uma no grupo dos velhos com hipotireoidismo estava com epitelização incompleta. A mucosa já mostrava diferenciação celular com o aparecimento de células caliciformes e organização glandular e as túnicas da parede estavam parcialmente organizadas .

A análise do conteúdo total de colágeno revelou, no $3 .^{\circ}$ dia, que as anastomoses de jovens e velhos tinham o mesmo comportamento, porém via-se menos colágeno nas anastomoses dos animais com hipotireoidismo. Este comportamento se manteve no $7 .^{\circ}$ e no $14 .^{\circ}$ dia (Quadro 1 e Figura 2).

QUADRO 1 - Média do percentual de colágeno encontrado nas anastomoses dos 4 grupos

\begin{tabular}{|c|c|c|c|}
\hline \multirow[b]{2}{*}{ GRUPO } & \multicolumn{2}{|c|}{$\begin{array}{l}\% \text { da área examinada ocupado po } \\
\text { ágeno }\end{array}$} & \multirow[b]{2}{*}{$14 .^{\circ} \mathrm{dia}$} \\
\hline & $3 .^{o}$ dia & 7. ${ }^{\circ}$ dia & \\
\hline Jovens normais (JN) & $20,03 \pm 1,41$ & $37,51 \pm 2,95$ & $39,43 \pm 5,03$ \\
\hline Velhos normais (VN) & $19,73 \pm 2,21$ & $37,73 \pm 6,48$ & $41,39 \pm 6,38$ \\
\hline Jovens hipotireoideanos (JH) & $11,28 \pm 2,35$ & $20,29 \pm 0,94$ & $29,51 \pm 5,01$ \\
\hline Velhos hipotireoideanos (VH) & $11,27 \pm 2,60$ & $20,14 \pm 2,37$ & $24,57 \pm 2,66$ \\
\hline \multicolumn{4}{|c|}{ 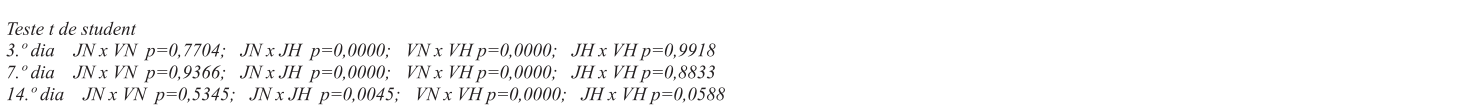 } \\
\hline
\end{tabular}

A concentração de colágeno I era menor nas anastomoses dos animais hipotireoideanos, tanto em jovens como em velhos, nos 3 tempos estudados (Quadro 2, Figura 2). A

concentração de colágeno III era mais baixa nos jovens e nos velhos com hipotireoidismo nas avaliações de 7 e de 14 dias (Quadro 3 e Figura 2).

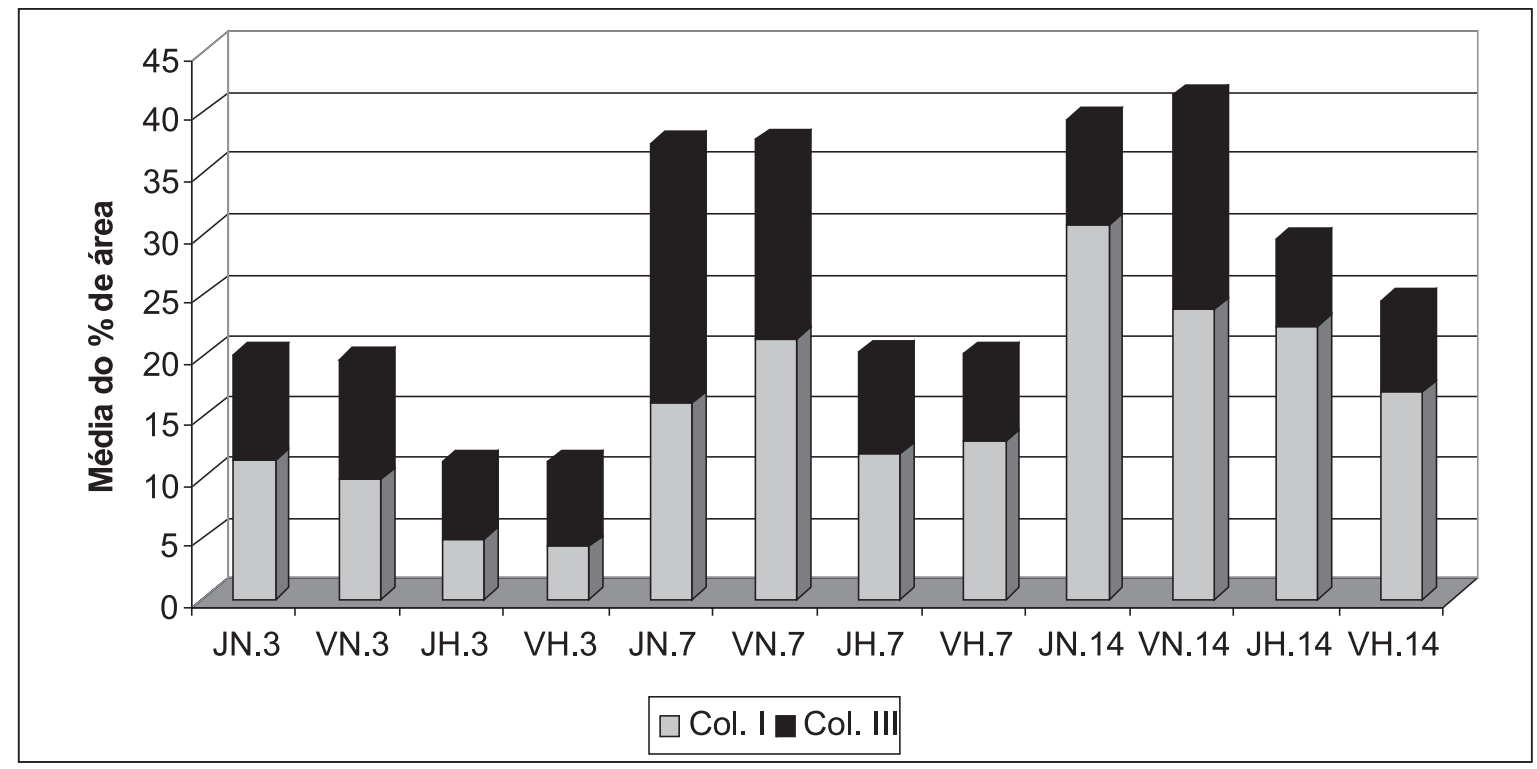

FIGURA 2 - Média do percentual das áreas das cicatrizes das anastomoses ocupadas por colágeno I e III, nos 3 tempos estudados, nos 4 grupos 
QUADRO 2 - Média do percentual de colágeno I encontrado nas anastomoses dos 4 grupos

\begin{tabular}{|c|c|c|c|}
\hline \multirow[b]{2}{*}{ GRUPO } & \multicolumn{3}{|c|}{$\%$ da área examinada ocupado por colágeno I } \\
\hline & 3. ${ }^{\circ}$ dia & 7. ${ }^{\circ}$ dia & $14 .^{\circ} \mathrm{dia}$ \\
\hline Jovens normais & $11,48 \pm 3,66$ & $13,14 \pm 1,88$ & $30,75 \pm 5,64$ \\
\hline Velhos normais & $9,88 \pm 1,82$ & $21,43 \pm 2,60$ & $23,80 \pm 3,95$ \\
\hline Jovens hipotireoideanos & $4,95 \pm 1,12$ & $11,92 \pm 1,20$ & $22,53 \pm 4,93$ \\
\hline Velhos hipotireoideanos & $4,30 \pm 1,01$ & $12,97 \pm 2,75$ & $17,00 \pm 3,05$ \\
\hline \multicolumn{4}{|c|}{ 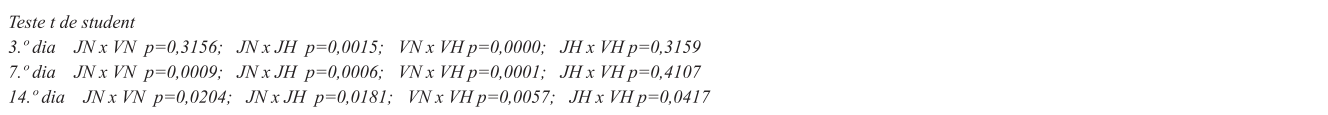 } \\
\hline
\end{tabular}

QUADRO 3 - Média do percentual de colágeno III encontrado nas anastomoses dos 4 grupos

\begin{tabular}{|c|c|c|c|}
\hline \multirow[b]{2}{*}{ GRUPO } & \multicolumn{3}{|c|}{ \% da área examinada ocupado por colágeno III } \\
\hline & 3. ${ }^{\circ}$ dia & $7 .^{\circ} \mathrm{dia}$ & $14 .^{\circ} \mathrm{dia}$ \\
\hline Jovens normais & $8,54 \pm 2,95$ & $21,37 \pm 2,67$ & $8,67 \pm 4,96$ \\
\hline Velhos normais & $9,86 \pm 1,93$ & $16,30 \pm 4,56$ & $17,59 \pm 3,70$ \\
\hline Jovens hipotireoideanos & $6,04 \pm 2,68$ & $8,38 \pm 1,08$ & $6,98 \pm 2,26$ \\
\hline Velhos hipotireoideanos & $6,97 \pm 1,70$ & $7,17 \pm 1,68$ & $7,57 \pm 1,57$ \\
\hline
\end{tabular}

\section{Discussão}

A melhora das técnicas de diagnóstico e das terapêuticas aliadas à melhora das condições de vida permitiu o envelhecimento da população, não só nos países industrializados da Europa e América do Norte, mas também em nosso país. Isto tem feito aumentar o número de intervenções em idosos. Muitos cirurgiões acreditam que a idade avançada produza modificações fisiológicas que comprometem a cicatrização.

Alguns estudos clínicos multicêntricos apontam a idade como fator de risco para a cicatrização ${ }^{2,3}$ e pesquisadores demonstraram, em idosos, atraso de epitelização ${ }^{4,5}$ e baixa da concentração de colágeno I. Estes dados foram confirmados em camundongos e ratos . ASHCROFT et al observaram, em camundongos, baixa concentração de colágeno I, mas também de colágeno III.

Enquanto alguns pesquisadores descrevem que fibroblastos senescentes são incapazes de responder a estímulos mitogênicos ${ }^{21}$ outros, afirmam que não existem evidências de que a resposta de fibroblastos humanos aos fatores de crescimento, seja afetada pela idade ${ }^{8}$.

Existem relatos de que o hipotireodismo diminua a síntese, a concentrac̃ão, a sensibilidade e o metabolismo do colágeno ${ }^{12,13}$. YAO e EGHBALI ${ }^{15}$ descreveram em modelo experimental, em camundongos, envolvimento direto do hormônio tireoideano na modulação da expressão do gen para o colágeno I e LEE et al ${ }^{16}$ identificaram mecanismos moleculares envolvidos na indução do hormônio tireodeano regulando o
RNA mensageiro para o colágeno I. O hipotireoidismo levava à inibição da síntese do colágeno, mostrado pela falta de fibrose induzindo à hipertrofia ventricular esquerda e baixa concentração do colágeno intracelular nos fibroblastos cardíacos. URABE et al ${ }^{22}$ relataram que na reparação de fraturas, de ratos com hipotireoidismo, existia diminuição da ossificação endocondral, intramembranossa e da condrogênese.

ELDOGAN et al ${ }^{17}$ já haviam observado, em estudo experimental feito com ratos com hipotireoidismo induzido com 5-propul,2-thiuracil, diminuição da resistência das cicatrizes abdominais $(\mathrm{p}<0,001)$ e da concentração de hidroxiprolina $(\mathrm{p}<0,001)$, apenas nas observações do $14 .^{\circ}$ dia. Para eles a resistência era dependente tanto da quantidade de colágeno quanto da organização, visto que nos ratos com hipotireoidismo encontraram não só diminuição da concentração de colágeno mas também atraso da organização.

NATORI et al ${ }^{18}$ descreveram, em feridas abdominais de ratos com hipotireoidismo cirúrgico, importante diminuição da concentração de hidroxiprolina no $7 .^{\circ}$ dia $(p<0,05)$ e no $14 .^{\circ}$ dia $(\mathrm{p}<0,01)$ com importante declínio do colágeno IV em todos os tempos $(\mathrm{p}<0,02)$. O hormônio tireoideano estaria associado com a proliferação e a secreção dos fibroblastos. A supressão da secreção dos hormônios tireoideanos causaria distúrbio da ativação metabólica nos tecidos e na síntese do colágeno, se estendendo da fase inflamatória até a fase proliferativa. Apesar disso GROMAKOVA et al ${ }^{23}$ afirmaram que o hipotireoidismo não afeta de forma significante a síntese do colágeno, sendo as alterações decorrentes do 
envelhecimento. Devemos lembrar que os estudos aqui relatados, abordavam, ora idosos, ora hipotireoideanos e que as 2 situações não foram tratadas simultaneamente.

Deficiências de cicatrização da parede abdominal aumentam a possibilidade de infecção e morte. Quando se verificam deiscências de anastomoses digestivas a situação é ainda mais grave. Na literatura revisada não se encontrou menção aos efeitos do hipotireoidismo sobre anastomoses intestinais.

Em estudo de nossa linha de pesquisa observou-se que, embora existam diferenças no processo de cicatrização de jovens e velhos, a idade, por si só, não é a causa da falência da cicatrização, tanto nas feridas da parede abdominal, quanto nas das anastomoses colônicas ${ }^{19}$.

Neste estudo, associando-se envelhecimento e hipotireoidismo, a análise da resistência das anastomoses demonstrou que estas eram, no início, no $7 .^{\circ}$ dia, menos resistentes nos jovens não sendo influenciada pelo estado tireoidiano. A concentração de colágeno sofreu interferência do estado hormonal, sendo mais baixa nos hipotireoideanos, tanto jovens como velhos, tanto no início do processo como nas fases mais avançadas. Estes achados são verificados em relação ao colágeno I e ao III o que permite admitir que existe não só baixa da síntese de colágeno, mas também da maturação das cicatrizes. Parece que o envelhecimento não foi a causa mais importante destas alterações, visto que as cicatrizes dos animais jovens também as apresentavam. Estes resultados se assemelham muito aos descritos por NATORI et al ${ }^{18}$. Entretanto, estas deficiências não foram importantes a ponto de levar a falência das anastomoses, visto que não se observaram deiscências. De qualquer forma, isto deve manter o alerta de que em situações de hipotireoidismo, os cuidados técnicos precisam ser redobrados.

\section{Conclusão}

A análise dos resultados permite concluir que existe diminuição da concentração de colágeno decorrente da baixa da síntese e retardo de maturação das cicatrizes das anastomoses muito mais às custas do hipotireoidismo do que do envelhecimento.

\section{Referências}

1. Bufalari M, Ferri M, Lolli G, Fabbri C, Bisacci R. La chirurgia generale nel paziente ottuagenario. Minerva Chir. 1996; 51:383-8.

2. Riou JP, Cohen JR, Johnson H. Factors influencing wound dehiscense. Am J Surg. 1992; 163:324-30.

3. Carlson MA. Acute wound failure. Surg Clin North Am. 1997; 77:607-36

4. Gilchrest BA. In vitro assessment of keratinocyte aging. J Invest Dermatol. 1983; 81(1 Suppl):184s-9s.
5. Holt DR, Kirk SJ, Regan MC, Hurson M, Lindblad WJ, Barbul A. Effect of age on wound healing in healthy human beings. Surgery. 1992; 112:293-8.

6. Reed MJ, Corsa A, Pendergrass W, Penn P, Sage EH, Abrass IB. Neovascularization in aged mice: delayed angiogenesis is coincident with decreased levels of transforming growth factor beta 1 and type I collagen. Am J Pathol. 1998; 152:113-23

7. Ashcroft GS, Kielty CK, Horan MA, Ferguson MW. Age-related changes in the temporal and spatial distribitions of fibrilin and elastin mRNAs and proteins in acute cutaneous wounds of healthy humans. J Pathol. 1997; 183:80-9.

8. Kletsas D, Pratsinis H, Zervolea I, Handris P, Sevaslidou E, Ottaviani E, Stathakos D. Fibroblast responses to exogenous and autocrine factors relevant to tissue repair: the effect of aging. Ann N Y Acad Sci. 2000; 908:155-66.

9. Oliveira ILC. Avaliação das funções tireóideas em idosos. [Tesedoutorado]. Salvador: Universidade Federal da Bahia; 1998.

10. Schindler AE. Thyroid function and postmenopause. Gynecol Endocrinol. 2003; 17:79-85.

11. Alexander MV, Zajtchuk JT, Henderson RL. Hypothyroidism and wound healing. Arch Otolaryngol. 1982; 108:289-91.

12. Kivirikko KI, Laitinen O, Aer J, Halme J. Metabolism of collagen in experimental hyperthyroidism and hypothyroidism in the rat. Endocrinology. 1967:80:1051-61.

13. Kowalewski K, Yong S. Hydroxyproline in healing dermal wounds of normal and hypothyroid rats. Acta Endocrinol. 1967; $54: 1-7$.

14. Senda Y, Nishibu M, Kawai K, Mizukami Y, Hashimoto T. Evaluation of type IV collagen in patients with various thyroid disease. Rinsko Byori. 1993; 41:1338-42.

15. Yao J, Eghbali M. Decreased collagen mRNA and regression of cardiac fibrosis in the ventricular myocardium of the tight skin mouse following thyroid hormone treatment. Cardiovasc Res. 1992; 26:603-7.

16. Lee HW, Klein LE, Raser J, Eghbali-Webb M. An activator protein-1 (AP-1) response element on pro alpha (1) collagen gene is necessary for thyroid hormon-induced inhibition for promoter activity in cardiac fibroblasts. J Mol Cell Cardiol. 1998; 30:2495506.

17. Erdogan M, Ilhan YS, Akkus MA, Caboglu AS, Ozercan I, Ilhan N, Yaman M. Effects of L-thyroxine and zinc therapy on wound healing in hypothyroid rats. Acta Chir Belg. 1999; 99:72-7.

18. Natori J, Shimizu K, Nagahama M, Tanaka S. The influence of hypothyroidism on wound healing. J Nippon Med Sch. 1999; 66:176-80

19. Biondo-Simões MLP. Os efeitos do envelhecimento na cicatrização: avaliação da parede abdominal e de anastomoses colônicas, em ratos. 2001. Curitiba, 168p (Tese-Professor Titular - Pontifícia Universidade Católica do Paraná

20. Junqueira LCU, Bignolas G, Brentani RR. Picrosirius staining plus polarization microscopy, a specific method for collagen detection in tissue sections. Histochem J. 1979; 11:447-55. 
21. Cristofalo VJ, Pignolo RJ. Replicative senescence of human fibroblast like cells in culture. Physiol Rev. 1993; 73:617-38.

22. Urabe K, Hotokebuchi T, Oles KJ, Bronk JT, Jingushi S, Iwamoto Y, Bolander ME. Inhibiton of endochondral ossification during fracture repair in experimental hypotiroid rats. J Orthop Res. 1999; 17:920-5.

23. Gromakova IA, Zilberman ST, Konovalenko AO. Age-related changes of protein- and RNA synthetic processes in experimental hyper- and hipothyroidism. Biochemistry (Mosc). 2001; 66:7638.

Biondo-Simões MLP, Ioshii SO, Zazula AD, Biondo-Simões R. The healing inffluenced by hypotireoidism and elderly. Study of intestinal anastomosis healing in rats. Acta Cir Bras [serial on line] Available from: URL: htt://www.scielo.br/acb.

ABSTRACT - Turpose: The aging of the population has led to an increased number of interventions in elderly patients, with hypothyroidism, even at the subclinical level, being a common situation among these patients. The objective of the present study was to determine the influence of hypothyroidism on the healing process of colon anastomoses in aged rats. Methods: 96 male Wistar rats were used, 48 of them young and 48 old. Half the young animals and half the old ones were euthyroid and half were hypothyroid. Hypothyroidism was obtained by total thyroidectomy. Thirty days after surgery the animals were submitted to median laparotomy followed by transverse colotomy of the left colon with end-to-end anastomosis and laparorrhaphy. Six animals from each group were submitted to euthanasia by drawing lots on the $3^{\text {rd }}, 7^{\text {th }}$ and $14^{\text {th }}$ postoperative day and submitted to macroscopic, resistance, and histopathological analysis of the anastomoses. Results: No dehiscence was observed and the gain of resistance and the general histological evolution in terms of epithelialization and inflammatory reaction was similar in all groups. Analysis of total collagen content revealed that the anastomoses of young and old animals showed the same behavior on the 3rd day, although less collagen was observed in hypothyroid animals $(\boldsymbol{Y N} x \mathbf{Y H} \boldsymbol{p}=\mathbf{0 . 0 0 0 0 ;} \mathbf{O N} \boldsymbol{x} \mathbf{O H} \boldsymbol{p = 0 . 0 0 0 0})$. This behavior persisted on the 7th and $14^{\text {th }}$ day. Less collagen I was present in the anastomoses of hypothyroid animals on the $3^{\text {rd }}(\boldsymbol{Y N} \boldsymbol{x} \mathbf{Y H} \boldsymbol{p}=\mathbf{0 . 0 0 1 5} ; \boldsymbol{O N} \boldsymbol{x} \boldsymbol{O H}$ $p=0.0000), 7$ th $(Y N x Y H p=0.0006 ; O N x O H p=0.0001)$ and $14^{\text {th }}$ day $(Y N x Y H p=0.0181 ; O N x O H p=0.0057)$, the same occurring for collagen III on the $3^{\text {rd }}(\boldsymbol{x} Y H p=0.0007 ; O N x O H p=0.0260)$, 7th $(Y N x Y H p=0.0160 ; O N x O H p=0.2670)$ and $14^{\text {th }}$ day $(Y N x Y H$ $p=0.0000 ; \mathrm{ON} x \mathrm{OH} p=0.0030$ ). Conclusion: Analysis of the results permitted us to conclude that lower collagen concentration due to low synthesis and delayed scar maturation in the anastomoses occurred and was much more due to hypothyroidism than to aging.

KEYWORDS: Wound healing. Colon. Collagen. Hypothyroidism. Aging.

Correspondência:

Rua Ari José Valle, 1987, Santa Felicidade

CEP 82030-000, Curitiba-Paraná

Telefone 0XX41.297.43.59

e-mail: biondo@avalon.sul.com.br 